\title{
Research Article \\ Effect of Natural Fillers on Mechanical Properties of GFRP Composites
}

\author{
Vikas Dhawan, ${ }^{1}$ Sehijpal Singh, ${ }^{2}$ and Inderdeep Singh ${ }^{3}$ \\ ${ }^{1}$ Research Scholar, Mechanical \& Production Engineering Department, GNDEC, Punjab Technical University, \\ Ludhiana 141 010, Punjab, India \\ ${ }^{2}$ Mechanical \& Production Engineering Department, GNDEC, Punjab Technical University, Ludhiana 141 010, Punjab, India \\ ${ }^{3}$ Department of Mechanical and Industrial Engineering, Indian Institute of Technology Roorkee, Roorkee 247 667, India
}

Correspondence should be addressed to Inderdeep Singh; dr.inderdeep@gmail.com

Received 26 January 2013; Revised 2 June 2013; Accepted 14 June 2013

Academic Editor: Masamichi Kawai

Copyright (C) 2013 Vikas Dhawan et al. This is an open access article distributed under the Creative Commons Attribution License, which permits unrestricted use, distribution, and reproduction in any medium, provided the original work is properly cited.

Fiber reinforced plastics (FRPs) have replaced conventional engineering materials in many areas, especially in the field of automobiles and household applications. With the increasing demand, various modifications are being incorporated in the conventional FRPs for specific applications in order to reduce costs and achieve the quality standards. The present research endeavor is an attempt to study the effect of natural fillers on the mechanical characteristics of FRPs. Rice husk, wheat husk, and coconut coir have been used as natural fillers in glass fiber reinforced plastics (GFRPs). In order to study the effect of matrix on the properties of GFRPs, polyester and epoxy resins have been used. It has been found that natural fillers provide better results in polyester-based composites. Amongst the natural fillers, in general, the composites with coconut coir have better mechanical properties as compared to the other fillers in glass/epoxy composites.

\section{Introduction}

The widespread use of the fiber reinforced plastics (FRPs) over the last few years has led to the increased research interest in the area of FRPs. Though the synthetic fiber reinforced plastics possess excellent properties, their cost of processing is quiet high, mainly due to the material cost. On the other hand, the use of natural fibers leads to cost reduction and light weight composites, though the mechanical properties of natural fiber composites are much lower as compared to the synthetic fiber composites [1]. Hence, researchers all around the world have resorted to hybrid composites by combining natural fibers with synthetic fibers in a common matrix. Mohan et al. [2] found that longitudinal compressive strength of jute-glass hybrid composites increases with increase in glass content whereas transverse compressive strength is even lower than that of jute composites. In another research effort it was found that water absorption increased with jute-glass hybrid composites which lead to decrease in mechanical properties [3]. The mechanical properties such as tensile, flexural, interlaminar shear strength, impact strength, notch sensitivity, and water absorption of jute-glass reinforced composites were studied and it was found that the mechanical properties are lower than those of plain GFRP and more than the jute fiber reinforced composites $[1,4,5]$. Water absorption was found to increase with the increase in jute content. A self-healing hybrid polymer composite of jute and glass fiber was developed to eliminate delamination and to obtain lighter composites with lower maintenance costs [6]. Thermal conductivity and thermal diffusivity were found to increase with the increase in glass content in a hybrid pineapple leaf and glass fiber reinforced polyester composite [7]. In a study made on Cordenka fiber reinforced polypropylene composites with partial jute fibers, it was concluded that the stiffness and heat distortion temperatures increased with the increase in jute proportion while the tensile strength and impact strength decreased [8]. John and Venkata Naidu [9-11] studied the tensile, impact, flexural, and 
compressive properties of sisal fiber and glass fiber hybrid composites with polyester as matrix material. The properties were studied for different glass contents and were found to improve with increasing glass percentages. The variation of tensile and flexural properties of Sisal/Carbon fiber hybrid composites with different fiber weight ratios were studied and significant improvement in these mechanical properties was observed with $\mathrm{NaOH}$ treatment of sisal fibers. It was found in chemical resistance tests that hybrid composites were not resistant to carbon tetra chloride [12]. Thermal conductivity of unsaturated polyester-based sisal/glass fiber hybrid composites was found to be lower than that of glass fiber reinforced composites and more than that of sisal fiber reinforced composites. It was also found that adding chalk powder to the resin also increased thermal conductivity [13]. Tewari et al. [14] found that mixing bagasse fiber with glass fiber improves the modulus of elasticity and impact strength but decreases the ultimate strength and bending strength. Sorption behavior and environmental aging in tensile properties were studied for short bamboo fiber reinforced polypropylene and short bamboo-glass fiber reinforced polypropylene composites. Later hygrothermal aging and fatigue behavior under cyclic loading were also studied. Tensile strength and elastic modulus of the two composites reduced considerably after aging at $75^{\circ} \mathrm{C}$ for 3 months [15, 16]. Cicala et al. [17] proposed that a cost reduction of $20 \%$ and a weight reduction of $23 \%$ could be achieved by using natural fibers along with glass fibers for the purpose of design of pipes. Two types of hybrid composites were fabricated in rooflite resin, one by mixing palmyra and glass fiber and the other by sandwiching palmyra fiber between glass fiber mats. The glass fiber skin with palmyra fiber core showed better mechanical properties than the dispersed one [18]. Rice husk along with glass fibers and unsaturated polyester was found to produce composites with acceptable properties [19]. Ultraviolet radiation pretreated jute and glass fiber hybrid composites were found to exhibit better mechanical properties than untreated jute-glass hybrid composites [20]. Coir-glass hybrid polyester composites were found to be promising candidates for structural applications where high strength and stiffness are required [21]. The tensile behavior of coir-glass hybrid composites at different temperatures was studied with coir and glass fibers in equal proportions. The mechanical strength increased with the increase in temperature after $50^{\circ} \mathrm{C}$ but reduced considerably at higher temperatures $\left(100^{\circ} \mathrm{C}\right)$, especially for high fiber volume fractions [22]. From the literature it is clear that mechanical properties of the composites made by hybridization of natural fibers with synthetic fibers are lower than those of composites made with synthetic fibers alone. In order to reduce the cost and weight of the composites, natural fibers are used along with synthetic fibers. In the present research endeavor, coconut coir, wheat husk, and rice husk have been used as fillers along with glass fibers to form GFR-Polyester-based and GFR-Epoxy-based composites. The effect of the addition of natural fillers along with the effect of using different resin material on the mechanical properties of the GFRPs has been studied.

\section{Experimental Details}

2.1. Fabrication of Epoxy Laminates with Natural Fillers and Glass Fibers. Composite laminates of $4 \mathrm{~mm}$ thickness were prepared using boron-free EC-R glass mats, epoxy resin, and natural fillers. Rice husk, wheat husk, and coconut coir were used as filler materials. Composite laminates were prepared by conventional hand layup technique in chrome plated mild steel mold, $560 \mathrm{~mm}$ by $460 \mathrm{~mm}$ at room temperature. The mold is specially designed to produce $4 \mathrm{~mm}$ thick laminate sheets. All the composites have 6 layers of woven boron-free EC-R glass fiber mats of 610 GSM manufactured by Owens Corning Fiber Glass, USA. The EC-R glass had a young's modulus of $80 \mathrm{GPa}$ and density of $2.62 \mathrm{~g} / \mathrm{cm}^{3}$. Epoxy resin LY556 (density $1.15-1.20 \mathrm{~g} / \mathrm{cm}^{3}$ at $25^{\circ} \mathrm{C}$ ) and hardener HY 951 (density $1 \mathrm{~g} / \mathrm{cm}^{3}$ at $20^{\circ} \mathrm{C}$ ) were used. The resin and hardener were mixed and stirred mechanically in a ratio of $10: 1$ by weight. In order to follow a standard comparative procedure, it was decided to fabricate laminates with a thickness of $4 \mathrm{~mm}$. The natural fillers were used in a proportion of $5 \%$ of the weight of glass fibers. The decision to add only 5\% natural fillers was taken after a pilot study. Initially, $10 \%$ natural fillers were added and a remarkable decrease in the mechanical properties was observed. The reduction in the properties may be attributed to the nonwetting of the fibers and fillers by the polymer matrix and agglomeration of the fillers. Moreover, the thickness constraint of $4 \mathrm{~mm}$ was also not achieved with the addition of $10 \%$ fillers. Here, it is worthwhile to mention that natural fibers before use were reduced to a size of one to four $\mathrm{cm}$ in length. Initially, the work side of the mold was coated with a thin layer of PVA (Poly Vinyl Alcohol) which acts as a release agent. After the PVA coating has dried, a light layer of the resin is made with the help of a brush and then the first layer of woven glass sheet is placed in the lower part of the mold. The glass sheet is thoroughly coated with the resin with the help of a brush and then one-fifth of the filler is evenly spread over the layer and the second glass layer is placed. Again, the resin is applied thoroughly so that the resin drips down the glass layer and coats the natural fibers also. This process is continued till the final layer of glass mat is coated with the resin. The top plate of the mold is then properly placed over the lower one to complete the assembly. Finally, the complete mold is placed in a press and a compression load of 15 tonnes is applied. The compression ensures that the entrapped air bubbles are completely removed and the excess resin flows out. The mold is left for 10 hours at room temperature to complete the curing process. The same technique was used to fabricate the other laminates. In all, four different types of specimens were fabricated. Three of the GFR-epoxy-based composites consisted of different natural biofillers, that is rice husk, wheat husk, and coconut coir, as fillers and the fourth laminate had glass fiber alone as a reinforcement.

2.2. Fabrication of Unsaturated Polyester Laminates with Natural Fillers and Glass Fibers. General purpose polyester resin (density $1.1 \mathrm{~g} / \mathrm{cm}^{3}$ ) was used along with Methyl Ethyl Ketone Peroxide (MEKP) and Cobalt Octoate. First, the general 
purpose resin was mixed with Cobalt Octoate (with 6\% Cobalt content) which acts as an accelerator. The accelerator accelerates the decomposition of organic peroxide initiators called catalysts and in turn increases the polymerization. Then just before the application of the resin to glass fiber, MEKP is added to the resin which acts as a catalyst and initiates the polymerization of polyester resins. MEKP also helps in cold setting of polyester-based composites. As the sheets were made in summers with normal temperature being around 40 degree plus in India, just $10 \mathrm{~mL}$ of Cobalt Octoate and $10 \mathrm{~mL}$ of MEKP were added to the resin. It has to be kept in mind that once MEKP has been added to the resin, the hand layup process has to be completed quickly; otherwise, the resin starts to gel and leads to wastage. The manufacturing of polyester-based glass fiber sheets with natural fillers is done in the same way as the epoxy-based sheets. The natural fibers are again used in the proportion of $5 \%$ by weight of the glass fiber weight and initially hand-layup process is used and then the complete mold assembly is subjected to compressive force of 15 tonnes in a press. The polyester-based laminates get ready for use within 3 hours. Similar to the epoxy-based FRP laminates; four polyester-based FRP sheets were prepared. One with woven glass fiber alone and other three laminates are with different natural fillers, that is, wheat husk, rice husk, and coconut coir.

\section{Mechanical Characterization}

3.1. Tensile Strength. The tensile test was performed in accordance with ASTM D3039. The test specimen size was $250 \mathrm{~mm} \times 25 \mathrm{~mm} \times 4 \mathrm{~mm}$. The test was performed on a universal testing machine (UTM) of 10-tonne capacity. The flat specimens of required size were fixed between the grips of each head of the testing machine in a way that the direction of force applied to the specimen is coincident with the longitudinal axis of the specimen. The strain rate was so selected so as to produce the failure from 1 to $10 \mathrm{~min}$ :

$$
\text { Tensile Strength }=\frac{W}{B D}
$$

$W=$ Load in Kgs, $B=$ Breadth in $\mathrm{cm}$, and $D=$ thickness in $\mathrm{cm}$.

3.2. Compressive Strength. The compressive strength of the test specimens was found using UCSB compressive fixture [23]. The size of the test specimens was $127 \mathrm{~mm} \times 38.1 \mathrm{~mm}$ $\times 4 \mathrm{~mm}$. A hole of $6.35 \mathrm{~mm}$ was then drilled in the center of the flat specimens. The test was performed on a universal testing machine of 10-tonne capacity. The test specimens were fixed in a UCSB fixture and the fixture was placed in between two flat circular plates on the UTM. The compressive load was applied in the axial direction so as to cause the failure of the specimen.

$$
\text { Compressive Strength }=\frac{W}{B D}
$$

$W=$ Load in Kgs, $B=$ Breadth in $\mathrm{cm}, D=$ thickness in $\mathrm{cm}$.
3.3. Cross Breaking Strength. The cross breaking test was conducted as per IS: $1998-1962$. According to the IS standards, the test specimen needs to be $15 \mathrm{~mm} \pm 0.5 \mathrm{~mm}$ in breadth and should have a length of 24 to 30 times the thickness of the laminate measured nearest to $0.03 \mathrm{~mm}$. The test was conducted on the UTM. Two parallel V-shaped supports were used to fix the specimen in the machine. The distance between the supports was kept equal to sixteen times the measured thickness of the test specimen. A load was applied by the third V-block parallel to and between the supporting blocks across the width of the test specimen. The load was steadily increased at such a rate that the test specimen fractures in 15 to 45 seconds from the time of initial application of load:

$$
\text { Cross Breaking Strength }=\frac{1.5 W L}{B D^{2}}
$$

$W=$ Load in kgs, $L=$ Distance between supports in $\mathrm{cm}, B=$ Breadth in $\mathrm{cm}$, and $D=$ Thickness in $\mathrm{cm}$.

3.4. Izod Impact Strength. Izod Impact Strength was found according to IS0 180:1993, on an Izod Impact Testing Machine (0-168 Joule capacity). A rectangular piece of length $63.5 \pm 2 \mathrm{~mm}$ and width $12.7 \pm 0.2 \mathrm{~mm}$ having thickness of the laminate $(4 \mathrm{~mm})$ was prepared as shown in Figure 1 . The specimen is having a $\mathrm{V}$-notch at a point equidistant from the ends of the long side. The specifications of the specimen as per the standard are shown in Figure 1. The specimen was fixed in the vice of the testing machine so that the notched face of the specimen faces the striker and the root of the notch is in level with the horizontal face of the vice. When the pendulum is released with the help of an operating lever, the notched side of the specimen is struck by the striking edge of the pendulum. The energy absorbed in breaking the specimen was then recorded:

$$
\begin{aligned}
& \text { Izod Impact Strength }\left(\mathrm{KJ} / \mathrm{m}^{2}\right) \\
& =\frac{\text { Energy absorbed in joules }}{\text { Width of notched face } \times \text { Length below the notch }} .
\end{aligned}
$$

3.5. Rockwell Hardness Test. Test specimens of size $25 \mathrm{~mm}$ by $25 \mathrm{~mm}$ were prepared according to ASTM D785-08. A steel ball indenter of $3.175 \mathrm{~mm}$ diameter was used to find the hardness on a Rockwell machine. The hardness was measured on Rockwell hardness K-scale with a major load of $150 \mathrm{~kg}$ and an average of five hardness tests was taken.

3.6. Specific Gravity Test. The specific gravity test was done in accordance with Indian Standard IS: 10192-1982. The specimen prepared for the test was a square of $40 \pm 1 \mathrm{~mm}$ with thickness being that of the laminate $(4 \mathrm{~mm})$. The specimen was first weighed in air by suspending it with the help of a thread fixed to the hook of the balance, and the weight $W_{1}$ was recorded. Then, the weight $W_{2}$ was recorded by measuring the specimen in fresh distilled water. The specimen was allowed to attain the temperature of the water by immersing it in water 

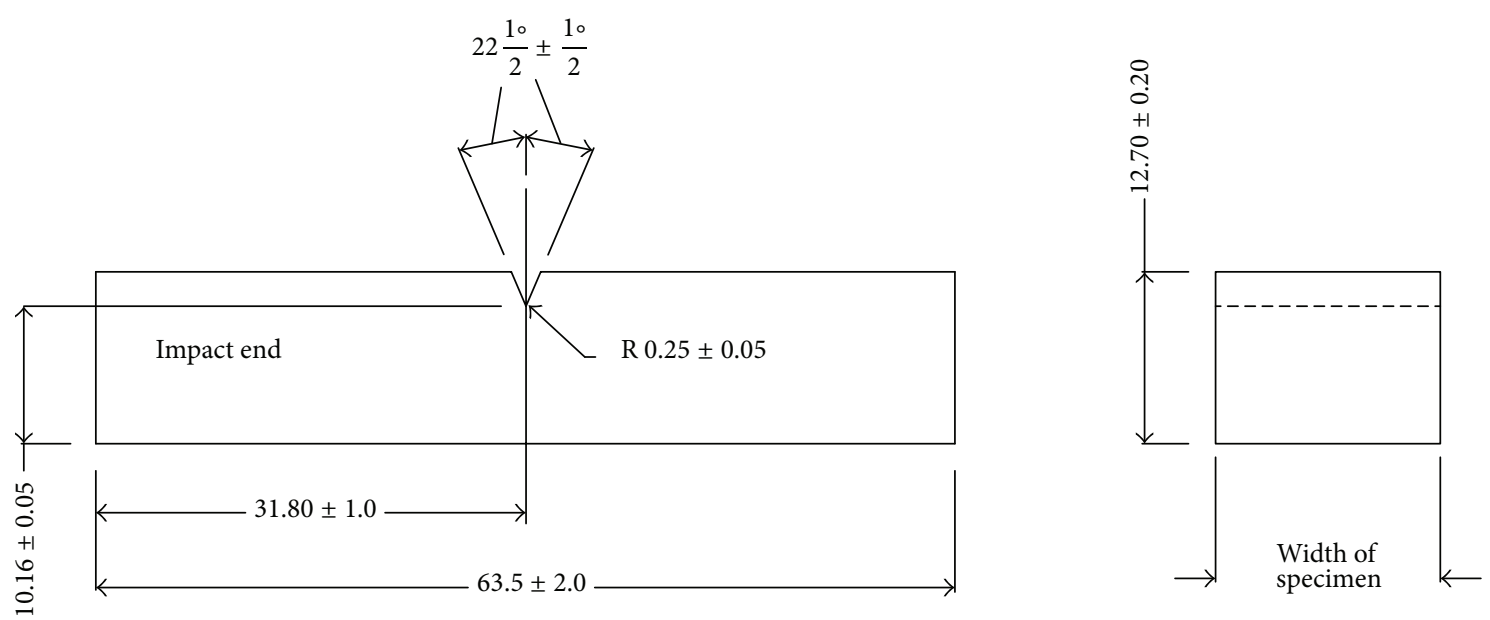

FIGURE 1: Specimen for Izod Impact Strength.

for sufficient time. Care was also taken that no air bubbles stick to the specimen:

$$
\text { Specific gravity }=\frac{W_{1}}{W_{1}-W_{2}} .
$$

3.7. Water Absorption Test. The water absorption test was conducted according to Indian Standard IS: 1998-1962. A square test specimen of $38_{-0.0}^{+0.5} \mathrm{~mm}$ was made. The weight of the specimen was first measured in air $\left(W_{1}\right)$, and then the specimen was immersed in distilled water for a period of $24 \pm 1$ hour. On removal from water, the specimen was wiped properly and was weighed within two minutes of its removal from water. This weight was recorded as $W_{2}$ :

$$
\text { Water Absorption }=\frac{W_{2}-W_{1}}{W_{1}} \times 100 .
$$

3.8. Volume Fraction of Glass Fibers. The volume fraction of glass fibers (glass content) was found according to ASTM D2584-08. The test specimens of $20 \mathrm{~mm} \times 20 \mathrm{~mm} \times 4 \mathrm{~mm}$ were prepared. Initially, a desiccated ceramic crucible was weighed $\left(W_{1}\right)$, and then it was weighed along with the specimen $\left(W_{2}\right)$. Then, the crucible with the specimen was placed in a muffle furnace at $590^{\circ} \mathrm{C}$. After the carbonaceous material disappeared, the crucible was cooled to a room temperature and the crucible was weighed again with glass fibers left alone $\left(W_{3}\right)$ :

$$
\text { Ignition Loss }=\frac{W_{2}-W_{3}}{W_{2}-W_{1}} \times 100
$$$$
\text { Glass Content }=100-\text { Ignition Loss. }
$$

\section{Results and Discussion}

In all, eight different types of GFRP laminates were fabricated. Four of the GFRPs were epoxy resin based and other four were general purpose polyester (orthophthalic resin commonly known as G. P resin) based. In general, with the same resin, one specimen was reinforced with glass fiber alone and three other were reinforced with different natural fillers that is wheat husk, Rice husk, and coconut coir. Various characterization tests were conducted and their results are depicted in Table 1 and are discussed in the following sections.

4.1. Tensile Strength. In general, it has been found that the tensile strength of epoxy-based GFRPs is more than polyester-based composites. The tensile strength values of the eight different composites under consideration are shown in Figure 2. Though the tensile strength of composites developed with epoxy and polyester decreases when the natural fillers are added, the tensile strength of epoxy-based composites with coconut coir and wheat husk as fillers is greater than the plain glass reinforced polyester composites. On the contrary, the composites developed with rice husk fillers in polyester show more strength than the composites developed in epoxy with rice husk as fillers. The reason may be attributed to the better bonding of rice husk with polyester rather than with epoxy. The epoxy-based composites with coconut coir as fillers show comparable strength with plain GFRP composites, and on the other hand, polyester-based composites with rice husk fillers show good tensile strength in comparison to other polyester-based composites with fillers. The tensile strength of the epoxy-based composites decreased by a maximum of $22.8 \%$ (with rice husk fillers) and that of polyester-based composites decreased by $19.71 \%$ (with wheat husk fillers).

4.2. Compressive Strength. The compressive strength was found using UCSB fixture on Universal Testing Machine. The compressive strength of epoxy-based composites is more than that of polyester-based composites as shown in Figure 3. The compressive strength of all the composites with and without fillers with epoxy as matrix is more than glass fiber reinforced polyester laminates. This shows that epoxy should 
TABLE 1: Summary of experimental findings.

\begin{tabular}{|c|c|c|c|c|c|c|c|c|}
\hline \multirow{3}{*}{ Property } & \multicolumn{8}{|c|}{ FRP } \\
\hline & \multicolumn{4}{|c|}{ Glass fiber reinforced epoxy } & \multicolumn{4}{|c|}{ Glass fiber reinforced polyester } \\
\hline & No filler & $\begin{array}{l}\text { Wheat husk } \\
\text { filler }\end{array}$ & $\begin{array}{l}\text { Coconut coir } \\
\text { filler }\end{array}$ & $\begin{array}{l}\text { Rice } \\
\text { filler }\end{array}$ & No filler & $\begin{array}{l}\text { Wheat husk } \\
\text { filler }\end{array}$ & $\begin{array}{c}\text { Coconut coir } \\
\text { filler }\end{array}$ & $\begin{array}{l}\text { Rice } \\
\text { filler }\end{array}$ \\
\hline Tensile strength $\left(\mathrm{N} / \mathrm{mm}^{2}\right)$ & 398.73 & 353.05 & 372 & 307.65 & 352.5 & 283 & 315 & 324.9 \\
\hline Compressive strength $\left(\mathrm{N} / \mathrm{mm}^{2}\right)$ & 351.3 & 222.24 & 289 & 280.43 & 212.9 & 173.69 & 224.14 & 199.47 \\
\hline Cross breaking strength $\left(\mathrm{N} / \mathrm{mm}^{2}\right)$ & 896.07 & 698.03 & 827.45 & 733.33 & 614 & 522 & 702 & 548 \\
\hline Impact strength $\left(\mathrm{N} / \mathrm{mm}^{2}\right)$ & 263.84 & 206.47 & 214.84 & 234.37 & 234.37 & 245.53 & 278.93 & 256.69 \\
\hline Hardness (K-scale) & 56.1 & 30.33 & 42.83 & 40.33 & 41 & 33.25 & 35.9 & 41.375 \\
\hline Specific gravity & 1.6727 & 1.6152 & 1.6629 & 1.6166 & 2.082 & 1.6723 & 1.707 & 1.7272 \\
\hline Water absorption & 0.0343 & 0.6541 & 0.205 & 0.2316 & 0.47395 & 1.824 & 0.7522 & 0.685 \\
\hline Glass content & 52.14 & 54.77 & 52.83 & 55.55 & 52.39 & 54.02 & 51.41 & 53.19 \\
\hline
\end{tabular}

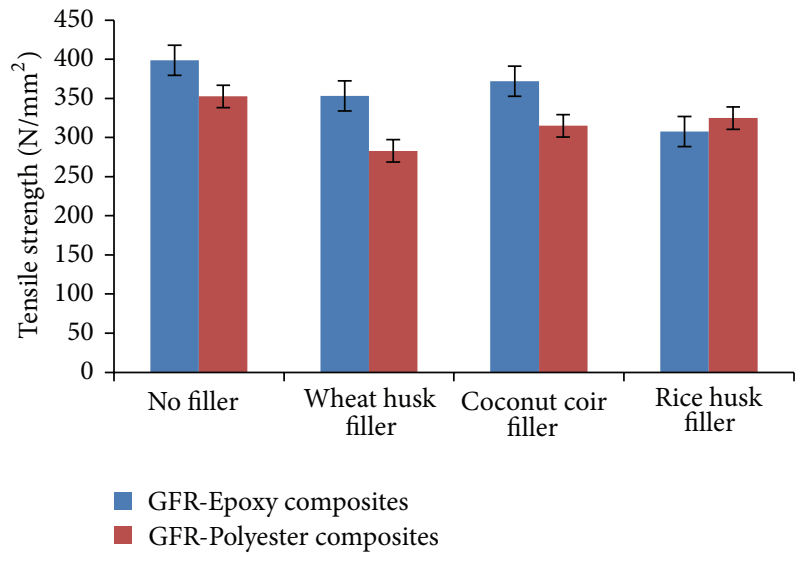

FIGURE 2: Tensile strength of composites with/without filler.

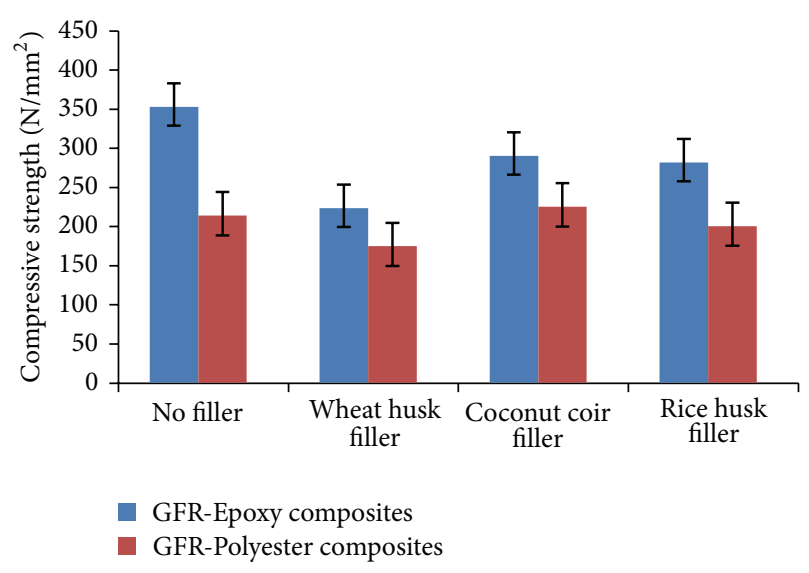

FIGURE 3: Compressive strength of composites with/without filler.

be used as matrix for better compressive strength. Amongst the GFR-Polyester composites, the specimens with coconut coir as filler show better compressive strength than the plain GFR-Polyester specimens. In general, the composites with wheat husk as fillers have the minimum compressive strength.

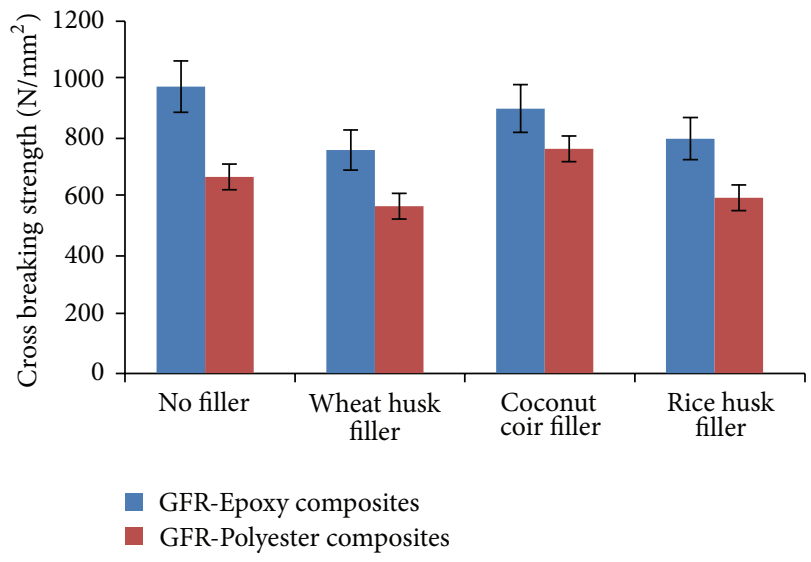

FIGURE 4: Results of three-point bending test.

The compressive strength of epoxy-based and polyesterbased composites decreased by a maximum of $36.7 \%$ and $18.41 \%$ on the addition of wheat husk fillers.

4.3. Cross Breaking Strength. The three-point bending test conducted on UTM shows that among the GFR-Polyester composites, the composites with coconut coir fillers show better strength than the plain GFR-polyester composites. Even in GFR-Epoxy composites, the specimens with coconut coir fillers show comparable strength to the plain GFR-Epoxy specimens. As shown in Figure 4, the cross breaking strength of GFR-Epoxy composites is better than GFR-Polyester composites. The cross breaking strength of composites with wheat husk fillers is lower in both GFR-Epoxy and GFRPolyester composites. The cross breaking strength of epoxybased composites decreased by $22.1 \%$ on the addition of wheat husk fillers whereas that of polyester-based composites increased by $14.33 \%$ on the addition of coconut coir fillers.

4.4. Impact Strength. Figure 5 clearly shows that the izod impact strength of polyester-based composites with coconut 


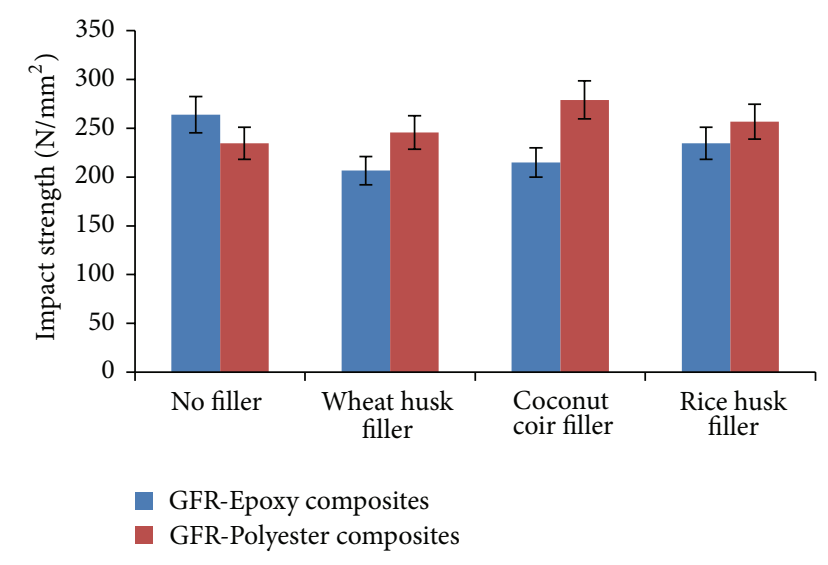

FIGURE 5: Izod Impact Strength of composites with/without filler.

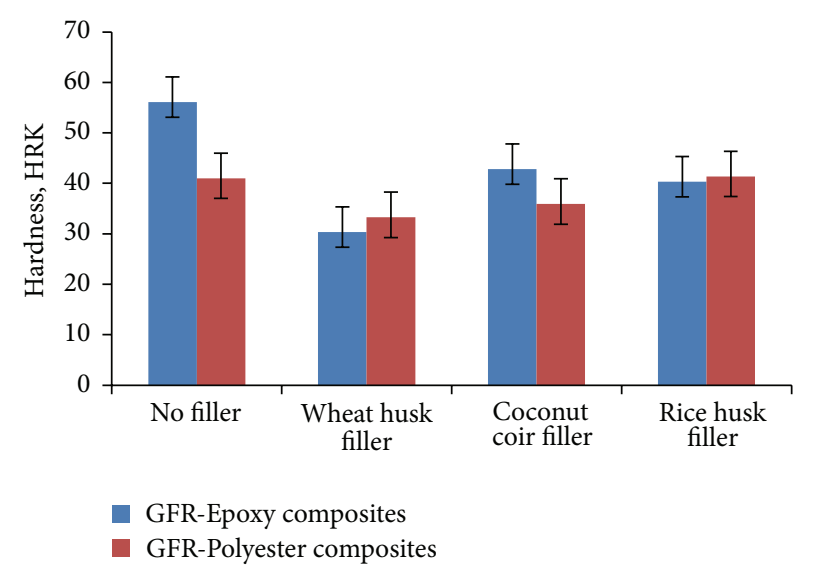

FIgURE 6: Hardness of composites with/without filler.

coir as fillers was found to be the best among all the composites fabricated. Different patterns were observed in epoxy- and polyester-based composites. In epoxy-based composites, plain GFRP specimens showed more impact strength followed by those with rice fillers, coconut coir fillers and the least impact strength was with wheat husk fillers, whereas in polyester-based composites, the highest impact strength was shown by specimens with coconut coir as fillers followed by those with rice husk fillers, wheat husk fillers, and the minimum impact strength was depicted by plain GFR-Polyester composites. On the whole it is observed that the impact strength improves in polyester-based composites on the addition of natural fillers. The impact strength of polyester-based composites increased by a maximum of $19.01 \%$ on the addition of coconut coir as fillers, but it reduced by $21.6 \%$ on the addition of wheat husk fillers in epoxy-based composites.

4.5. Hardness. The hardness of plain GFR-Epoxy composites was found to be maximum with a value of HRK 56.1. The hardness of GFR-Epoxy composites reduced with the addition of fillers. The hardness of GFR-Polyester with rice fillers was more than simple GFR-Polyester composites. The

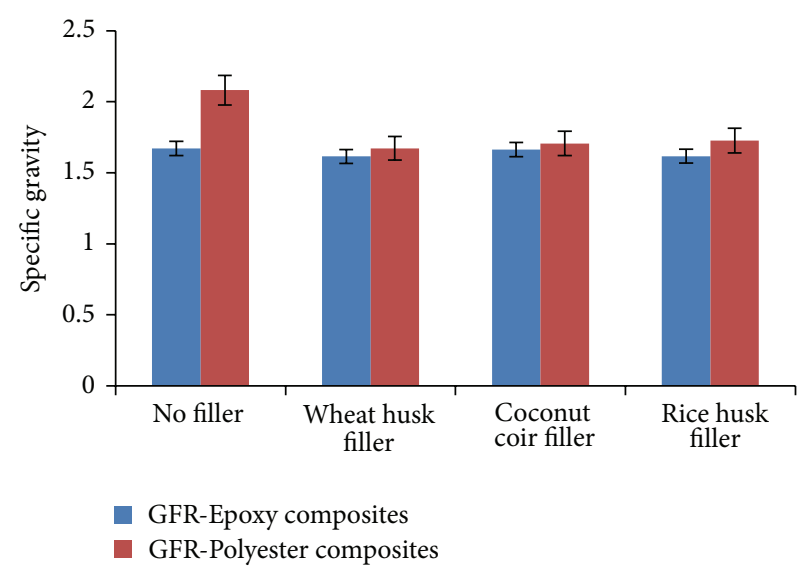

FIGURE 7: Specific gravity of composites with/without fillers.

hardness of composites with wheat husk as fillers was found to be the lowest with both epoxy and polyester as resin as shown in Figure 6. The hardness of epoxy-based composites decreased by $45.9 \%$ on the addition of wheat husk fillers and that of polyester-based composites increased by $0.91 \%$ on the addition of rice fillers.

4.6. Specific Gravity. The specific gravity of GFR-Polyesterbased composites is more than GFR-Epoxy-based composites. As is clear from Figure 7, the specific gravity of GFREpoxy composites is nearly the same whereas amongst the GFR-Polyester composites the specific gravity of plain GFR composites is found to be marginally more than those with fillers. The specific gravity of epoxy-based and polyesterbased reduced by a maximum of $3.39 \%$ and $19.67 \%$, respectively, on the addition of wheat husk fillers.

4.7. Water Absorption. Water absorption in case of GFRPolyester composites was found to be much greater than the GFR-Epoxy composites. Water absorption, even in GFREpoxy composites with fillers, is less than the plain GFRPolyester specimen. The test results of water absorption test are shown in Figure 8.

The water uptake may affect the mechanical behavior of the developed composites. It has already been established by the authors that the water uptake affects the tensile behavior of the polymer matrix composites [24, 25]. The researchers worldwide have tried to correlate the amount of water-up with the mechanical behavior of composite materials $[25,26]$.

4.8. Volume Fraction of Glass Fibers. The glass content for all the specimens is found to lie in the range of $51.4 \%-55.55 \%$. The variation is due to the variation in weight of glass fiber mats used.

\section{Conclusions}

In the present research endeavor, various characterization tests were conducted over GFR-Polyester- and GFR-Epoxybased composites. In general, the addition of fillers leads to 


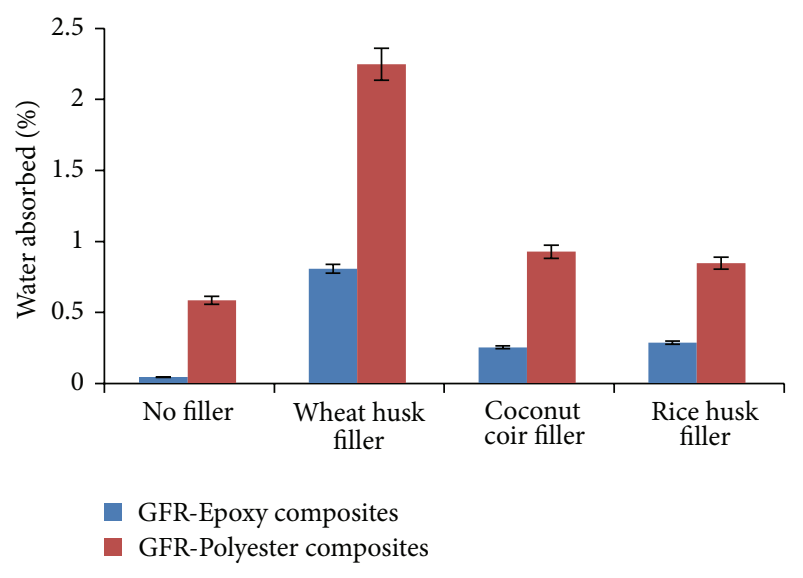

Figure 8: Results of Water Absorption Test.

cost and weight reduction of the regular glass fiber reinforced composites. The effect of the addition of natural fillers has been studied and the following conclusions can be drawn.

(1) The tensile strength of epoxy-based composites is better than that of polyester-based. The tensile strength of GFR-Epoxy composites with coconut coir as fillers is comparable to that of plain GFR-Epoxy composite and in case of polyester composites GFR-polyester with rice husk filler is comparable to that of plain GFR-Polyester laminate.

(2) The compressive strength of GFR-Epoxy-based composites is better than that of GFR-Polyester-based composites. The compressive strength of GFR-Polyester specimens with coconut coir as fillers results in better compressive strength than plain GFR-Polyester composites.

(3) The impact strength of polyester-based filler composites is better than that of epoxy-based composites. The impact strength of GFR-Polyester composites with coconut coir fillers is even more than the GFR-Epoxy composites with no fillers.

(4) The cross breaking strength of GFR-Epoxy composites is better than that of GFR-Polyester composites. Addition of coconut coir shows good results in both epoxy and polyester composites.

(5) The hardness of epoxy-based composites is more with respect to polyester-based composites.

(6) The specific gravity of polyester-based composites is more than epoxy-based composites. The addition of fillers leads to reduction of specific gravity in all types of composites investigated in the present research endeavor.

(7) Water absorption is more in polyester-based composites.

(8) Overall, coconut coir fillers should be used instead of wheat husk and rice husk in general to improve the properties of the developed glass fiber reinforced composite laminates.

\section{References}

[1] K. S. Ahmed and S. Vijayarangan, "Tensile, flexural and interlaminar shear properties of woven jute and jute-glass fabric reinforced polyester composites," Journal of Materials Processing Technology, vol. 207, no. 1-3, pp. 330-335, 2008.

[2] R. Mohan, K. Kishore, M. K. Shridhar, and R. M. V. G. K. Rao, "Compressive strength of jute-glass hybrid fibre composites," Journal of Materials Science Letters, vol. 2, no. 3, pp. 99-102, 1983.

[3] E. M. F. Aquino, L. P. S. Sarmento, W. Oliveira, and R. V. Silva, "Moisture effect on degradation of jute/glass hybrid composites," Journal of Reinforced Plastics and Composites, vol. 26, no. 2, pp. 219-233, 2007.

[4] K. S. Ahmed, S. Vijayarangan, and A. C. B. Naidu, "Elastic properties, notched strength and fracture criterion in untreated woven jute-glass fabric reinforced polyester hybrid composites," Materials and Design, vol. 28, no. 8, pp. 2287-2294, 2007.

[5] K. S. Ahmed, S. Vijayarangan, and C. Rajput, "Mechanical behavior of isothalic polyester-based untreated woven jute and glass fabric hybrid composites," Journal of Reinforced Plastics and Composites, vol. 25, no. 15, pp. 1549-1569, 2006.

[6] N. Abilash and M. Sivapragash, "Assesment of self healing property in hybrid fiber polymeric composite," International Journal of Engineering Science and Technology (IJEST), vol. 3, no. 7, pp. 5430-5435, 2011.

[7] M. Idicula, A. Boudenne, L. Umadevi, L. Ibos, Y. Candau, and S. Thomas, "Thermophysical properties of natural fibre reinforced polyester composites," Composites Science and Technology, vol. 66, no. 15, pp. 2719-2725, 2006.

[8] M. A. Khan, J. Ganster, and H.-P. Fink, "Hybrid composites of jute and man-made cellulose fibers with polypropylene by injection moulding," Composites A, vol. 40, no. 6-7, pp. 846-851, 2009.

[9] K. John and S. Venkata Naidu, "Sisal fiber/glass fiber hybrid composites: the impact and compressive properties," Journal of Reinforced Plastics and Composites, vol. 23, no. 12, pp. 1253-1258, 2004.

[10] K. John and S. V. Naidu, "Tensile properties of unsaturated polyester-based sisal fiber: glass fiber hybrid composites," Journal of Reinforced Plastics and Composites, vol. 23, no. 17, pp. 1815$1819,2004$.

[11] K. John and S. V. Naidu, "Effect of fiber content and fiber treatment on flexural properties of sisal fiber/glass fiber hybrid composites," Journal of Reinforced Plastics and Composites, vol. 23, no. 15, pp. 1601-1605, 2004.

[12] P. N. Khanam, H. P. S. A. Khalil, M. Jawaid, G. R. Reddy, C. S. Narayana, and S. V. Naidu, "Sisal/Carbon fibre reinforced hybrid composites: tensile, flexural and chemical resistance properties," Journal of Polymers and the Environment, vol. 18, no. 4, pp. 727-733, 2010.

[13] V. N. P. Naidu, G. R. Reddy, and M. A. Kumar, "Thermal conductivity of Sisal/Glass fibre reinforced hybrid composites," International Journal of Fiber and Textile Research, vol. 1, no. 1, pp. 28-30, 2011.

[14] M. Tewari, V. K. Singh, P. C. Gope, and A. K. Chaudhary, "Evaluation of mechanical properties of bagasse-glass fiber reinforced composite," Journal of Materials and Environmental Science, vol. 3, no. 1, pp. 171-184, 2012.

[15] M. M. Thwe and K. Liao, "Effects of environmental aging on the mechanical properties of bamboo-glass fiber reinforced polymer matrix hybrid composites," Composites $A$, vol. 33, no. 1, pp. 43-52, 2002. 
[16] M. M. Thwe and K. Liao, "Durability of bamboo-glass fiber reinforced polymer matrix hybrid composites," Composites Science and Technology, vol. 63, no. 3-4, pp. 375-387, 2003.

[17] G. Cicala, G. Cristaldi, G. Recca, G. Ziegmann, A. El-Sabbagh, and M. Dickert, "Properties and performances of various hybrid glass/natural fibre composites for curved pipes," Materials and Design, vol. 30, no. 7, pp. 2538-2542, 2009.

[18] R. Velmurugan and V. Manikandan, "Mechanical properties of palmyra/glass fiber hybrid composites," Composites A, vol. 38, no. 10, pp. 2216-2226, 2007.

[19] H. D. Rozman, A. Hazlan, and A. Abubakar, "Preliminary study on mechanical and dimensional stability of rice husk-glass fiber hybrid polyester composites," Polymer-Plastics Technology and Engineering, vol. 43, no. 4, pp. 1129-1140, 2004.

[20] A.-A. Abdullah-Al-Kafi, M. Z. Abedin, M. D. H. Beg, K. L. Pickering, and M. A. Khan, "Study on the mechanical properties of jute/glass fiber-reinforced unsaturated polyester hybrid composites: effect of surface modification by ultraviolet radiation," Journal of Reinforced Plastics and Composites, vol. 25, no. 6, pp. 575-588, 2006.

[21] N. M. Kumar, G. V. Reddy, S. V. Naidu, T. S. Rani, and M. C. S. Subha, "Mechanical properties of coir/glass fiber phenolic resin based composites," Journal of Reinforced Plastics and Composites, vol. 28, no. 21, pp. 2605-2613, 2009.

[22] W. Yaakob, W. N. Azira, and A. E. Ismail, "Tensile behavior of hybrid natural/glass fibers reinforced composites at different temperatures," in Conference on Energy and Environment, Kuching, Sarawak, 2007.

[23] J. D. Bardis, K. T. Kedward, J. O. Bish, and T. K. Tsotsis, "Alternate compression test method for notched and unnotched composites," in Proceedings of the 45th International SAMPE Symposium and Exhibition, pp. 1149-1152, Long Beach, Calif, USA, May 2000.

[24] A. Agarwal, S. Garg, P. K. Rakesh, I. Singh, and B. K. Mishra, "Tensile behavior of glass fiber reinforced plastics subjected to different environmental conditions," Indian Journal of Engineering and Materials Sciences, vol. 17, no. 6, pp. 471-476, 2010.

[25] P. K. Bajpai, D. Meena, S. Vatsa, and I. Singh, "Tensile behavior of nettle fibercomposites exposed to various environments," Journal of Natural Fibers. In press.

[26] S. Tamrakar and R. A. Lopez-Anido, "Water absorption of wood polypropylene composite sheet piles and its influence on mechanical properties," Construction and Building Materials, vol. 25, no. 10, pp. 3977-3988, 2011. 

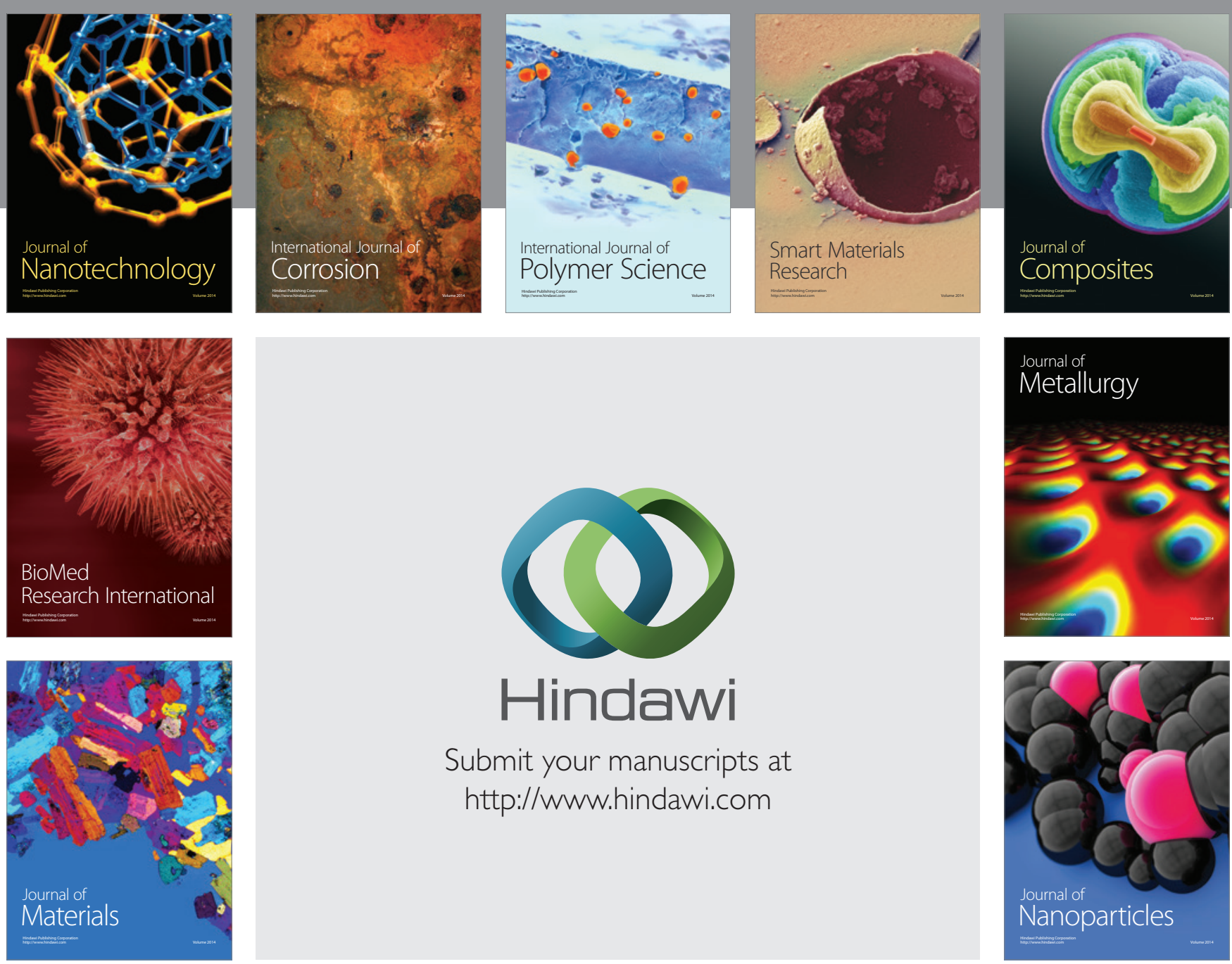

Submit your manuscripts at http://www.hindawi.com
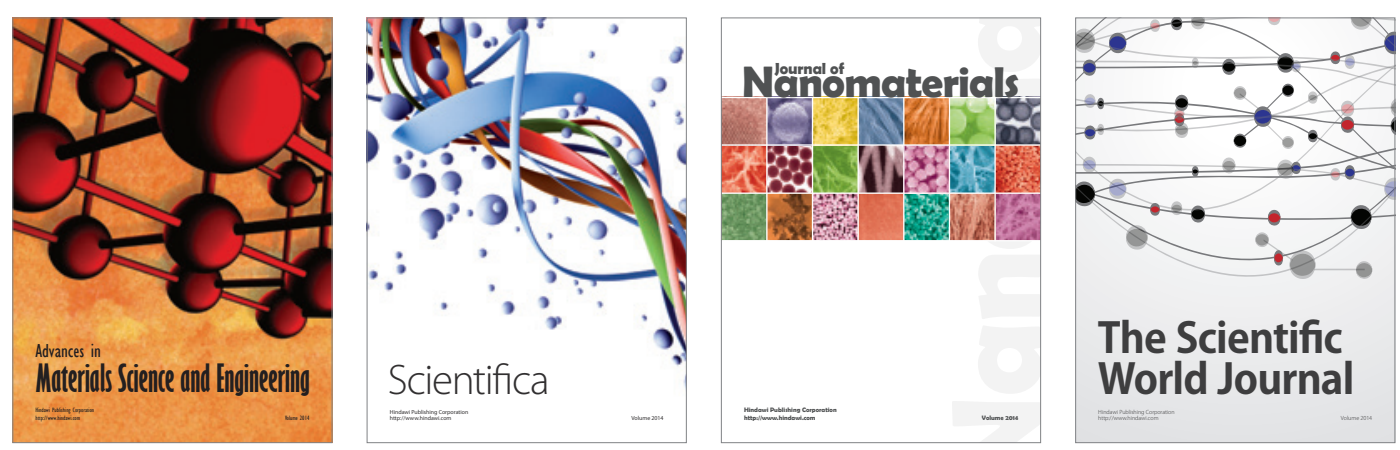

\section{The Scientific World Journal}
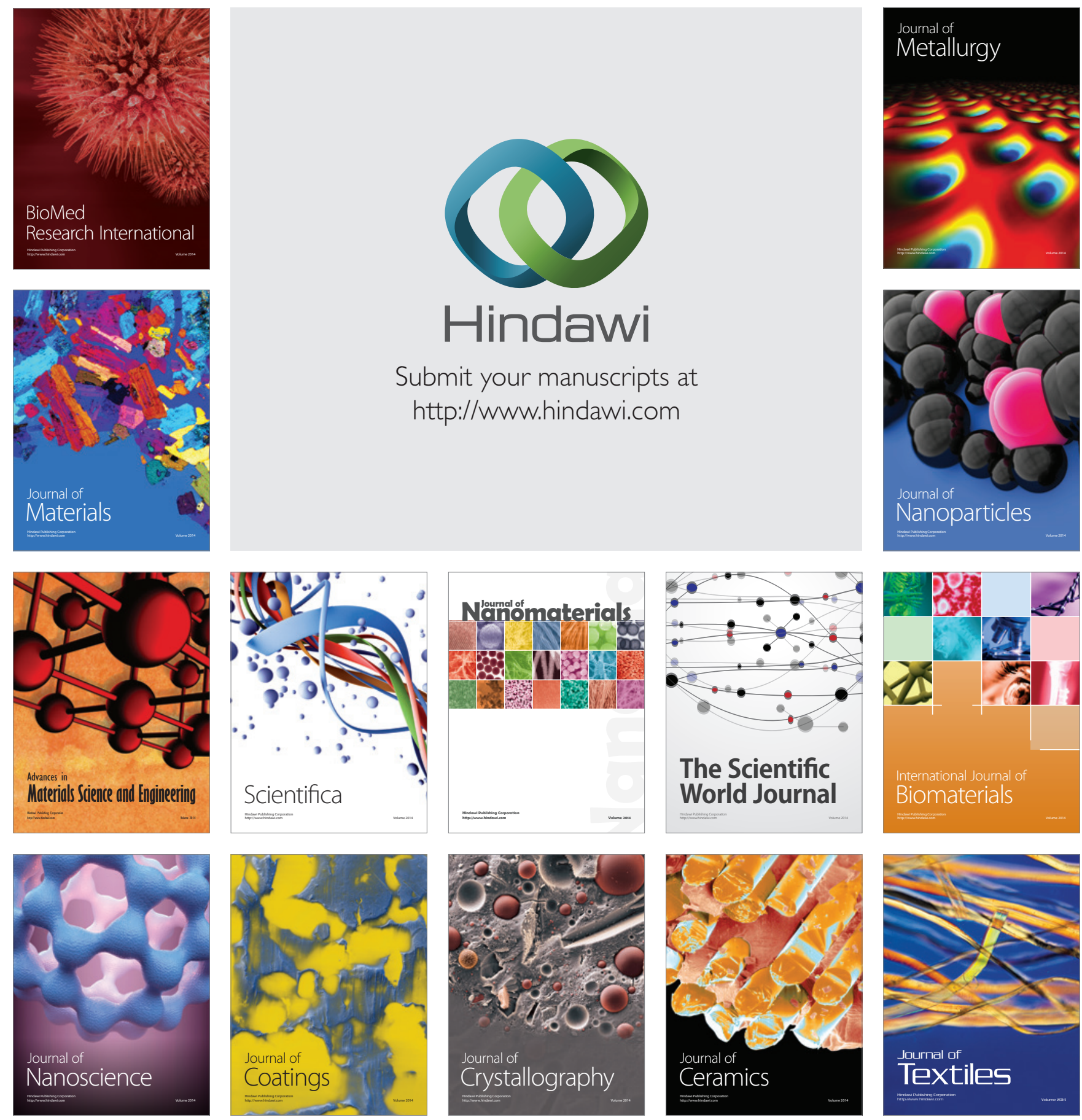